\title{
EJNSO
}

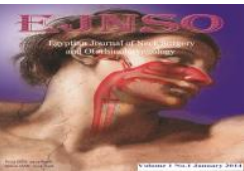

\section{Vestibular Functions in Hearing Impaired Children}

\author{
Mohamed Abd Al-Ghaffar a, Yousri Othman ${ }^{\mathrm{b}}$, Ashraf Abou-Taleb ${ }^{\mathrm{c}}$ \\ ${ }^{a}$ Audiology Unit, ENT Department, Faculty of Medicine, Sohag University \\ ${ }^{\mathrm{b}}$ ENT Department, Faculty of Medicine, Al-Azhar University \\ c Pediatric Department, Faculty of Medicine, Sohag University
}

Received: July $2^{\text {nd }}, 2013$.

Revised: September $16^{\text {th }}, 2013$

Accepted: November $15^{\text {th }}, 2013$

Keywords: vestibular functions. Hearing impairment, Ice caloric, VEMP, SOT-CDP.

\begin{abstract}
Objectives: To assess function of vestibular system through evaluation of vestibulo-ocular, vestibulocollic and vestibulospinal pathways in children with sensorineural hearing loss.

Method: 20 normal hearing children (control subjects) and 80 hearing impaired children were included in this study. The study group was classified as mild, moderate, severe, and profound according to their hearing threshold level. Ice caloric test (ICT), vestibular evoked myogenic potential (VEMP), and sensory organization test of computerized dynamic posturography (SOTCDP) were done to test the 3 vestibular pathways respectively.

Results: among the 80 hearing impaired children, 36 (45\%) were normal in the 3 tests, 20 patients $(25 \%)$ had abnormal results in one test only, $16(20 \%)$ were abnormal in 2 tests, and only 8 patients (10\%) showed abnormality in all 3 tests. 16 patients $20 \%$ were abnormal in ICT, 26 patients $(32.5 \%)$ had abnormal VEMP result, and 30 patients $(37.5 \%)$ had abnormal result in SOT- CDP. Significant moderate correlation was present between severity of hearing impairment and vestibulocular, vestibulocollic, and vestibulospinal pathway, $\mathrm{r}=0.422,0.485$, and 0.546 respectively.

Conclusion: the 3 vestibular pathways can be affected in the hearing-impaired children either separately or together.
\end{abstract}

\section{INTRODUCTION:}

The cochlear and vestibular organs are closely related anatomically and phylogenetically, and the relationship of vestibular function with hearing impairment has been discussed. Since the 1950s, many studies have been performed to establish the incidence of vestibular pathology in children with congenital and acquired deafness. ${ }^{(1-4)}$
Although these studies have employed the caloric test for the vestibulocular reflex function, most of them did not evaluate the other two reflexes; the vestibulocollic, and the vestibulospinal reflexes, whose functions may have more influence on the development of postural control and locomotion than the horizontal semicircular canals alone. ${ }^{(5-6)}$ 
Moreover, the recording of VEMPs induced in response to clicks or short toneburst stimuli has been carried out as a clinical test for the inferior vestibular nerve function since 1990s, and results suggest that VEMPs originate from the otolith organ, particularly the saccule. ${ }^{(7-8)} \mathrm{CDP}$ is a new test which assesses the vestibulospinal reflex which is responsible for maintenance and equilibrium. ${ }^{(9)}$

The importance of studying the relationship between vestibular function in the setting of deafness is underlined by the fact that sensorineural hearing loss is the most common congenital sensory impairment occurring in 3 out of every 1000 live births. ${ }^{(10)}$

Should even a small proportion of these individuals with SNHL exhibit concurrent vestibular involvement, this would still account for large numbers of individuals with vestibular dysfunction requiring identification, education and therapy.

\section{Aim of the work}

To assess vestibular functions in hearing impaired children.

\section{Subject and methods}

\section{I- Subjects}

The subjects were 100 children, 20 normal hearing (12 males and 8 females) with age range between 7 and 15 years and mean age $10.5 \pm 3.6$ in addition to 80 hearing impaired children ( 40 boys and 40 girls) with age range between 5 and 15 years and mean age $8.5 \pm 3.5$ years. The hearingimpaired children were classified into mild, moderate, severe, and profound according to their hearing threshold level.

\section{Exclusion criteria:}

Children with neuromotor or orthopedic dysfunction or on medication affecting central nervous system were excluded from the study.

Informed consent was obtained from the parents of all participants. The study was approved by Ethics Committee of Sohag Medical University.

\section{II-Equipment:}

1. Sound treated room IAC model, 1602.
2. Computerized two channel pure tone audiometer Madsen model,922.

3. Immitancemeter Amplaid model,775

4. Computerized Videonystagmography (VNG) ICs chartr.

5. Computerized auditory evoked potential, intelligent hearing system.

6. Vestibular Evoked Myogenic Potentials using a Synapsis evoked potential instrument

7. Computerized Dynamic Posturography system, Neurocom(Smart Equi-test).

\section{III- Methods}

Control and study groups were subjected to the following:

- Careful history taking with focus on the vestibular and hearing complaints.

- Basic audiological evaluation: behavioral audiometry, including air and bone conduction thresholds, speech audiometry, and tympanometry measurements which are very important to confirm normal middle ear pressure before VEMP testing. Auditory brainstem response was also used when it is necessary to establish or confirm the hearing loss.

\section{Vestibular assessment.}

The vestibular functions of the patients were evaluated by the following: ice-water caloric test, VEMP recording, and SOT of computerized dynamic posturography tests.

\section{- Assessment of the vestibulocular pathway:}

The ice-water (4C and 200ml) caloric test was performed by cold water using ICS Charte ${ }^{1} \mathrm{r}$ model, NCI- 480. Irrigation of the external auditory meatus to induce a thermal gradient across the horizontal semicircular canal of one ear. Horizontal and vertical eye movements (nystagmus) were recorded using standard videonystagmography.

- Assessment of vestibulocollic pathway

Saccular function was assessed using VEMP. The VEMP was evoked using a 105 dB click, administered through Telephonics TDH-39 headphones (Telephonics Huntington, NY). Electrodes were placed at 
the mid-point of the muscle belly of the sternocleidomastoid (SCM) bilaterally with a reference electrode on the ipsilateral mastoid tip. Subjects were instructed to turn their head towards the contralateral side to activate the SCM. At least 100 sweeps within the acceptance criteria were averaged. Averaged signals were then replicated at least once. A VEMP response was judged as either present or absent (unrecordable). A range of acceptable latencies of P13, N23 waveform were used (PI: $8.5-14 \mathrm{~ms}$; NI : $15-23 \mathrm{~ms}$ ) based on published age-appropriate ranges (11).The amplitude of the biphasic wave was measured bilaterally and an absolute VEMP ratio of $<0.5$ between the 2 sides was considered to indicate significant unilateral lesion. If the amplitude of p13-n23 was $<50 \mathrm{mV}$ on both sides, the subject was considered to have hypofunction bilaterally (bilateral decreased amplitude).

\section{SOT of Computerized dynamic posturography: \\ Computerized dynamic posturography} (Neurocom Smart Eque-test) quantitatively measures the patient's ability to maintain an upright posture in the face of varying somatosensory, visual, and vestibular inputs. Six conditions of the sensory organization are tested (see table 1). The child wears a small harness to be secured from falling during the various steps of the test. Force plates on which he or she stands detect the patient's sway. The patient's sway from upright in response to these situations is graded on the scale of 0 (fall) to 100 (no sway)..Three trials for each condition were performed. The score for each condition is calculated per child in addition to a composite score. The composite score is a weighted calculation of all conditions with emphasis upon the more difficult ones. Normal composite score is more than $60 \%$. It is considered abnormal if it is below $60 \%$. Condition 2 is abnormal if there is abnormal somatosensory input, condition 4 becomes abnormal if there is defect in the visual input, and conditions 3, 5, and 6 become abnormal if there is defective vestibular input to the brain.

\section{Statistical analysis}

Statistical analysis was done by SSPS version 11. For the water caloric test, the frequency of occurrence of normal, hypofunction (hyporeflexia), and areflexia were calculated for each subgroup in the study. For the VEMP results, the mean and standard deviation for P13 and N23 were calculated for each subgroup.

For the sensory organization test of CDP, the mean and standard deviation for each of the six conditions and the composite score were calculated.

Correlation factors were done to study the relationship between hearing impairment and vestibular impairment.

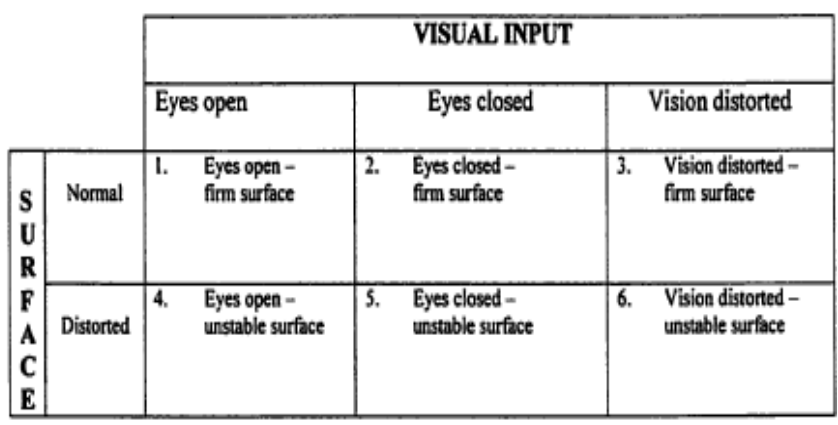

Table 1: The six conditions of the sensory organization test. 


\section{Results:}

This is a cross sectional study which included 100 children; 20 normal hearing (12 males and 8 females) with mean age $10.5 \pm 3.6$ in addition to 80 hearing impaired children (40 males and 40 females) with mean age 8.5. $\pm 3.5 y$ years. These children presented to the audiology and balance unit in Sohag University Hospital in the period from October 2009 to December 2012.

\section{Audiometric results}

The normal hearing- and hearingimpaired groups were assessed by the audiological evaluation.

\section{Vestibular examination}

\section{Ice caloric test}

Eighty children (160 ears) were tested by the ICT and the resulting ocular movement was recorded by videonystagmography. There are total 64 out of $80 \mathrm{HI}$ children (80 $\%)$ had normal ICT and $16(20 \%)$ with abnormal ICT; 2 HI children (2.5\%) with unilateral hyporeflexia, $2 \mathrm{HI}$ children $(2.5 \%)$ with unilateral areflexia, $6(7.5 \%)$ with bilateral hyporeflexia, and $6(7.5 \%)$ with bilateral areflexia.

\section{Vestibular evoked myogenic potential (VEMP)}

Among the 80 hearing impaired children, $54 \mathrm{HI}$ patients $(67.5 \%)$ had normal VEMP results and 26(32.5\%) HI subjects showed abnormal results in the form of prolonged P13 or N23 latency (unilateral in $7.5 \%$ and bilateral in 5\%), decreased amplitude in $4 \mathrm{HI}$ children $(5 \%)$, and unrecordable in 12 (15 $\%) \mathrm{HI}$ subjects either unilateral in $5 \%$ or bilateral in $10 \%$.
According to the previous results, the HI children were classified into 4 groups:

- Group A: includes the hearingimpaired children with normal vestibular function in all 3 tests. It included $36(45 \%)$ patients i.e they have normal SCCs, normal otolith organ and achieve good balance and equilibrium.

- Group B: includes the hearingimpaired children with normal vestibular function in 2 tests and abnormal in one test (mostly the posturography. It included $20(25 \%) \mathrm{HI}$ patients.

- Group C: includes the hearingimpaired children with normal vestibular function in 1 test and abnormal in 2 tests. It included 16 (20\%) HI children

- Group D: includes the hearingimpaired children with abnormal vestibular function in all 3 tests. It included 8 (10\%) HI children. 
Table 2: number of subjects, and mean \pm standard deviation for hearing level $(\mathrm{dB})$ in normal hearing- and hearing-impaired groups

\begin{tabular}{|l|l|l|l|l|l|}
\hline & $\begin{array}{l}\text { Normal } \\
\text { hearing } \\
(\text { Control) }\end{array}$ & Hearing impaired & severe & Profound \\
\cline { 3 - 7 } & 20 & 20 & 20 & 20 & 20 \\
\hline Number & & & & & \\
\hline Right ear hearing level & $15.3 \pm 3.5$ & $36.8 \pm 5.2$ & $48.6 \pm 6.5$ & $81 \pm 5.5$ & $97.6 \pm 9.5$ \\
\hline Left ear hearing level & $15.9 \pm 3.6$ & $37.1 \pm 4.1$ & $49.5 \pm 5.1$ & $82.2 \pm 4.5$ & $97 \pm 8.4$ \\
\hline
\end{tabular}

Figure 1 Pure tone audiometry of one patient in group A shows severe deafness.

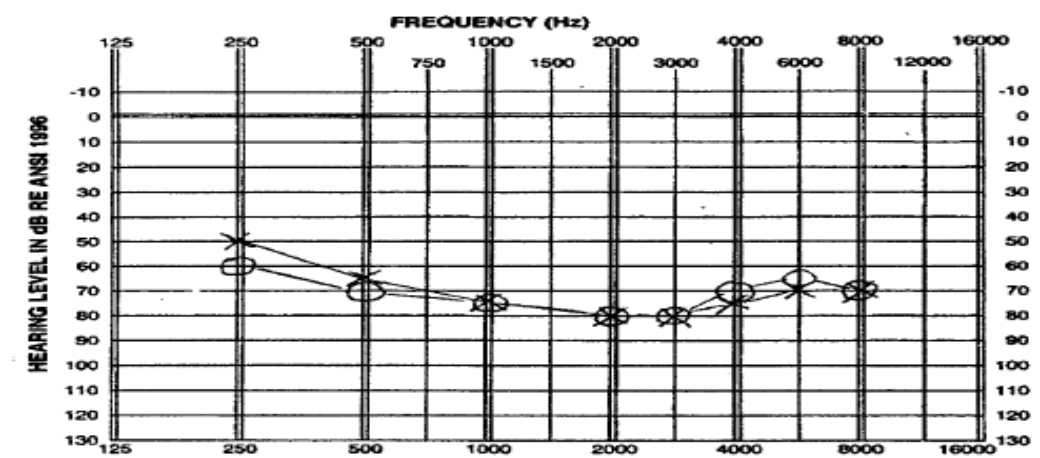

Table 3: ICT result, Frequency distribution and percentage ratio of normal and abnormal test result among hearing impaired children

\begin{tabular}{|c|c|c|c|c|c|c|}
\hline \multirow{2}{*}{$\begin{array}{l}\text { Result } \\
\text { HI } \\
\text { Groups }\end{array}$} & \multirow[t]{2}{*}{ Normal } & \multicolumn{2}{|l|}{ Unilateral } & \multicolumn{2}{|l|}{ Bilateral } & \multirow{2}{*}{$\begin{array}{l}\text { Total } \\
\text { HI } \\
\text { patients }\end{array}$} \\
\hline & & hyporeflexia & areflexia & hyporeflexia & areflexia & \\
\hline Mild HI & $20(100 \%)$ & $0(0 \%)$ & $0(0 \%)$ & $0(0 \%)$ & $0(0 \%)$ & 20 \\
\hline Moderate HI & $18(90 \%)$ & $0(0 \%)$ & $0(0 \%)$ & $2(10 \%)$ & $0(0 \%)$ & 20 \\
\hline Severe HI & $14(70 \%)$ & $2(10 \%)$ & $0(0 \%)$ & $2(10 \%)$ & $2(10 \%)$ & 20 \\
\hline Profound HI & $12(60 \%)$ & $0(0 \%)$ & $2(10 \%)$ & $2(10 \%)$ & $4(20 \%)$ & 20 \\
\hline Total HI & $64(80 \%)$ & $2(2.5 \%)$ & $2(2.5 \%)$ & $6(7.5 \%)$ & $6(7.5 \%)$ & 80 \\
\hline
\end{tabular}


Table 4: VEMP test result, Frequency distribution and percentage ratio of normal and abnormal among hearing impaired children

\begin{tabular}{|c|c|c|c|c|c|c|c|c|}
\hline \multirow{2}{*}{$\begin{array}{l}\text { Patient } \\
\text { subgroups }\end{array}$} & \multirow[t]{2}{*}{ Normal } & \multicolumn{3}{|l|}{ Unilateral } & \multicolumn{3}{|l|}{ Bilateral } & \multirow{2}{*}{$\begin{array}{l}\text { Tota } \\
\text { HI }\end{array}$} \\
\hline & & \begin{tabular}{l}
\multicolumn{2}{l}{ Prolonged } \\
p13 or \\
$\mathbf{N} 23$
\end{tabular} & $\begin{array}{l}\text { Decreased } \\
\text { amplitude }\end{array}$ & unrecordable & $\begin{array}{l}\text { Prolonged } \\
\text { p13 or N23 }\end{array}$ & $\begin{array}{l}\text { Decreased } \\
\text { amplitude }\end{array}$ & Unrecordable & \\
\hline Mild & $18(90 \%)$ & $2(10 \%)$ & $0(0 \%)$ & $0(0 \%)$ & $0(0 \%)$ & $0(0 \%)$ & $0(0 \%)$ & 20 \\
\hline Moderate & $16(80 \%)$ & $2(10 \%)$ & $0(0 \%)$ & $0(0 \%)$ & $2(10 \%)$ & $0(0 \%)$ & $0(0 \%)$ & 20 \\
\hline Severe & $10(50 \%)$ & $2(10 \%)$ & $0(0 \%)$ & $2(10 \%)$ & $2(10 \%)$ & $0(0 \%)$ & $4(20 \%)$ & 20 \\
\hline Profound & $10(50 \%)$ & $0(0 \%)$ & $2(10 \%)$ & $2(10 \%)$ & $0(0 \%)$ & $2(10 \%)$ & $4(20 \%)$ & 20 \\
\hline Total & $54(67.5 \%)$ & $6(7.5 \%)$ & $2(2.5 \%)$ & $4(5 \%)$ & $4(5 \%)$ & $2(2.5 \%)$ & $8(10 \%)$ & 80 \\
\hline
\end{tabular}

Figure 2: VEMP trace showing left decreased amplitude for a patient in group B

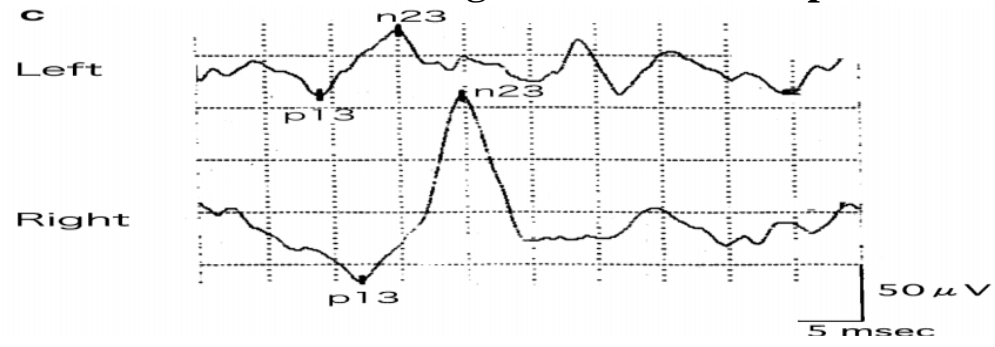

Table 5: SOT-CDP for the control and hearing impaired groups.Mean and standard deviation of the equilibrium scores in $\mathrm{HI}$ children

\begin{tabular}{|c|c|c|c|c|c|c|c|}
\hline $\begin{array}{l}\text { Test } \\
\text { Groups }\end{array}$ & $\begin{array}{l}\text { condition } \\
1\end{array}$ & $\begin{array}{l}\text { condition } \\
2\end{array}$ & $\begin{array}{l}\text { condition } \\
\mathbf{3}\end{array}$ & $\begin{array}{l}\text { condition } \\
4 \\
\end{array}$ & $\begin{array}{l}\text { Condition } \\
5 \\
\end{array}$ & $\begin{array}{l}\text { condition } \\
6 \\
\end{array}$ & $\begin{array}{l}\text { composite } \\
\text { score }\end{array}$ \\
\hline Control & $\begin{array}{l}91.8 \\
\pm 3.85\end{array}$ & $\begin{array}{l}86.95 \\
\pm 8.95\end{array}$ & $\begin{array}{l}89.85 \\
\pm 5.55\end{array}$ & $\begin{array}{l}76.55 \\
\pm 18.07\end{array}$ & $\begin{array}{l}63.25 \\
\pm 19.63\end{array}$ & $\begin{array}{l}59.9 \\
\pm 25.69\end{array}$ & $\begin{array}{l}69.9 \\
\pm 8.33\end{array}$ \\
\hline Mild HI & $\begin{array}{l}90 \\
\pm 4.320 \\
\text { NS } \\
\end{array}$ & $\begin{array}{l}87.3 \\
\pm 7.424 \\
\text { NS } \\
\end{array}$ & $\begin{array}{l}86.4 \\
\pm 7.106 \\
\text { NS } \\
\end{array}$ & $\begin{array}{l}65.5 \\
\pm 19.133 \\
\text { NS } \\
\end{array}$ & $\begin{array}{l}41.6 \\
\pm 23.552 *\end{array}$ & $\begin{array}{l}42 \\
\pm 26.221 \\
\text { NS } \\
\end{array}$ & $\begin{array}{l}68.9 \\
\pm 11.416 \\
\mathrm{NS} \\
\end{array}$ \\
\hline $\begin{array}{l}\text { Moderate } \\
\text { HI }\end{array}$ & $\begin{array}{l}89.4 \\
\pm 4.22 \mathrm{NS}\end{array}$ & $\begin{array}{l}90.1 \\
\pm 3.87 \mathrm{NS}\end{array}$ & $\begin{array}{l}85.9 \\
\pm 4.38 \mathrm{NS}\end{array}$ & $\begin{array}{l}64.4 \\
\pm 17.98 \mathrm{NS}\end{array}$ & $\begin{array}{l}30.2 \\
\pm 14.67 * * *\end{array}$ & $\begin{array}{l}29.4 \\
\pm 16.50^{* * *}\end{array}$ & $\begin{array}{l}65 \\
\pm 5.20^{*}\end{array}$ \\
\hline Severe HI & $\begin{array}{l}89.9 \\
\pm 2.234 \\
\text { NS }\end{array}$ & $\begin{array}{l}89.1 \\
\pm 1.853 \\
\text { NS }\end{array}$ & $\begin{array}{l}86.6 \\
\pm 2.633 \\
\text { NS }\end{array}$ & $\begin{array}{l}66.1 \\
\pm 13.972 \\
\text { NS }\end{array}$ & $\begin{array}{l}19.9 \\
\pm 18.729 \\
* * *\end{array}$ & $\begin{array}{l}22 \\
\pm 26.352 \\
* *\end{array}$ & $\begin{array}{l}62.4 \\
\pm 7.137 \\
*\end{array}$ \\
\hline $\begin{array}{l}\text { Profound } \\
\text { HI }\end{array}$ & $\begin{array}{l}89.7 \\
\pm 3.917 \\
\text { NS } \\
\end{array}$ & $\begin{array}{l}89.3 \\
\pm 5.034 \\
\mathrm{NS} \\
\end{array}$ & $\begin{array}{l}86.4 \\
\pm 3.406^{*}\end{array}$ & $\begin{array}{l}64.4 \\
\pm 13.468\end{array}$ & $\begin{array}{l}16.4 \\
\pm 17.92 \\
* * * \\
\end{array}$ & $\begin{array}{l}12.1 \\
\pm 14.548 \\
* * * \\
\end{array}$ & $\begin{array}{l}58 \\
\pm 8.273 \\
* * \\
\end{array}$ \\
\hline
\end{tabular}

NS: non-significant $\mathrm{P}$ vale $\quad * \mathrm{P}$ value significant at level $<0.05$

$* * \mathrm{P}$ value significant at level $<0.01 * * * \quad \mathrm{P}$ value significant at level $<0.001$ 
Table 6: ICT, VEMP and SOT-CDP, Frequency distribution and percentage ratio of normal and abnormal test result among hearing impaired children

\begin{tabular}{|l|l|l|l|l|l|l|}
\hline \multirow{2}{*}{ Groups } & \multicolumn{2}{|l|}{ Ice caloric test } & \multicolumn{2}{l|}{ VEMP } & \multicolumn{2}{l|}{ Posturography } \\
\cline { 2 - 7 } & Normal & abnormal & normal & abnormal & normal & Abnormal \\
\hline Mild & $20(100 \%)$ & $0(0 \%)$ & $18(90 \%)$ & $2(10 \%)$ & $16(80 \%)$ & $4(20 \%)$ \\
\hline Moderate & $18(90 \%)$ & $2(10 \%)$ & $16(80 \%)$ & $4(20 \%)$ & $16(80 \%)$ & $4(20 \%)$ \\
\hline Severe & $14(70 \%)$ & $6(30 \%)$ & $10(50 \%)$ & $10(50 \%)$ & $10(50 \%)$ & $10(50 \%)$ \\
\hline Profound & $12(60 \%)$ & $8(40 \%)$ & $10(50 \%)$ & $10(50 \%)$ & $8(40 \%)$ & $12(60 \%)$ \\
\hline Total & $64(80 \%)$ & $\begin{array}{l}16 \\
(20 \%)\end{array}$ & $\begin{array}{l}54 \\
(67.5 \%)\end{array}$ & $26(32.5 \%)$ & $\begin{array}{l}50 \\
(62.5 \%)\end{array}$ & $\begin{array}{l}30 \\
(37.5 \%)\end{array}$ \\
\hline
\end{tabular}

Table 7: Classification of patients according to results of vestibular function tests

\begin{tabular}{|l|l|l|l|l|l|}
\hline Groups & A & B & C & D & Total abnormal \\
\hline Mild & 16 & 4 & 0 & 0 & $4(20)$ \\
\hline Moderate & 12 & 4 & 4 & 0 & $8(40 \%)$ \\
\hline Severe & 6 & 6 & 6 & 2 & $14(70 \%)$ \\
\hline profound & 2 & 6 & 6 & 6 & $18(90 \%)$ \\
\hline Total abnormal & $36(45 \%)$ & $20(25 \%)$ & $16(20 \%)$ & $8(10 \%)$ & \\
\hline
\end{tabular}

A: number of cases with normal vestibular function according to the 3 vestibular tests

B: number of cases with single abnormal test. C: number of cases with 2 abnormal tests

D: number of cases with 3 abnormal tests.

Hearing level in relation to the ICT, VEMP and CDP

Table 8: Correlation between severity of hearing impairment and ICT, VEMP and SOT of CDP.

\begin{tabular}{|l|l|l|}
\hline Test & r-value & P-value \\
\hline Severity of hearing loss versus Ice caloric test & $\mathbf{0 . 4 2 2}$ & $\mathbf{0 . 0 3}$ \\
\hline Severity of hearing loss versus VEMP & $\mathbf{0 . 4 8 5}$ & $\mathbf{0 . 0 1}$ \\
\hline Severity of hearing loss versus CDP & $\mathbf{0 . 5 4 6}$ & $\mathbf{0 . 0 1}$ \\
\hline
\end{tabular}




\section{Discussion}

In this study, the 3 vestibular pathways; vestibulocular, vestibulocollic, and the vestibulospinal were investigated. The vestibular system was investigated by the ice caloric test as a powerful stimulus for the lateral semicircular canals. The response of the developing nystagmus was recorded by videonystagmography. So, this test evaluates the vestibulocular reflex arc from its receptor (the lateral SCCs) till its effector organ (external ocular muscles). If the degree of the developing nystagmus is more than 20 degree per second, then this reflex arc is normal. If the degree of the developing nystagmus is less than 20 degree per second, then there is hyporeflexia (hypofunction). If no nystagmus developed, then there is areflexia which occurs in case of agenesis or degeneration of the SCCs.

In this study, the frequency of abnormal caloric test (table: 3) is 20\%. (16 HI children), among them $2(2.5 \%)$ had unilareal hyporeflexia, $2(2.5 \%)$ unilalateral areflexia, $6(7.5 \%)$ bilateral hyporeflexia, and $6(7.5 \%)$ had bilateral areflexia.

This overall incidence falls within the reported range of 23 to $76 \%$ for the larger comparable studies in adults and children. (5,9,11-12,13-15) These results agree with data recorded by; Cushing et al (2008). Their results indicated an overall incidence of horizontal canal dysfunction of 53\% (17/32), $28 \%$ demonstrated complete horizontal canal dysfunction bilaterally (9/32), $0.03 \%$ complete unilateral dysfunction (1/32) while the remainder $(7 / 17)$ reflected mild $(n=6)$ to moderate $(n=1)$ unilateral hypofunction of the horizontal canal.

This incidence is lower than that of a previous pediatric cohort, where SCCs dysfunction was found to occur in nearly $70 \%$ of cases (14). Based on this figure, Buchman suggested that only a third of pediatric patients would be at risk of sustaining a vestibular injury due to cochlear implantation. Trying to interpret these results in same context as in Buchman's study, the proportions are reversed, with approximately $30 \%$ of children demonstrating complete horizontal canal dysfunction and $70 \%$ having normal of sufficient horizontal canal function to be at risk of a vestibular injury due to cochlear implantation.

A number of explanations could account for the differences in these studies. The most important difference may be reflected in the etiology distribution between the study groups. The etiology of the SNHL is an important predictor of peripheral vestibular function. The Buchman study does not provide the etiologic breakdown specifically for the pediatric cohort however if significant differences existed between the two study populations this would explain in part the differences in the incidence of horizontal canal function.

Vestibular evoked myogenic potential is another test which was used in this study to assess the vestibulocollic reflex. Hypofunction of the saccule is considered when there is prolonged latency or decreased amplitude of the biphasic wave. If the wave could not be recorded (unrecordable VEMP) then there is agenesis or degeneration in the saccule.

In this study abnormal VEMP results were recorded (table: 4) in $26(32.5 \%)$ patients out of the 80 hearing impaired children included in this study. Unilateral prolonged latency for p13 or N23 was recorded in $6(7.5 \%)$ cases, decreased amplitude in 2 cases $(2.5 \%)$, and unrecordable VEMP in $4(5 \%)$ cases. In addition to bilateral prolonged latencies in 4 (5\%) cases, decreased amplitude in $2(2.5 \%)$ cases, and unrecordable in $8(10 \%)$ cases. These results are in accordance with those obtained by many researchers. ${ }^{(5,9,15)}$ Cushing et al. in their study found that (38\%) of their study population demonstrated saccular dysfunction based on the absence of a VEMP response either bilaterally or unilaterally. The saccule is the vestibular end-organ that is most closely associated with the cochlea. During early development the otic vesicle divides into several chambers including a utricular chamber, which gives rise to the utricle and the 
semicircular canals, and a saccular chamber with gives rise to the saccule and the cochlea. ${ }^{(16,9)}$

Given the anatomic compartmentalization of the saccule and the cochlea one might predict that saccular function may be more likely to be affected than utricular or semicircular canal function in the presence of an inner ear injury leading to SNHL. this prediction is supported by our current findings in this study. Computerized dynamic posturography is a new test that monitors the role of somatosensory proprioceptive, visual, and labyrinthine input to control the balance and equilibrium of the subject by putting the person under 6 different conditions in a test known as sensory organization test. decreased equilibrium scores in condition 5 and 6 indicates that there is peripheral labyrinthine disorder or central along the vestibulospinal tract.

In this study, abnormal CDP result (table:5) was found in 30 patients (37.5\%). Abnormal scores in condition 5 and condition 6 were present in the 30 cases, and abnormal composite score were found in 20 (25\%) of them. Again, most abnormal results were found in the severe and profound hearing-impaired children group reaching $60 \%$ of cases. There is a statistically significant difference between the equilibrium scores in condition 5, 6 in the severe and profound cases when compared to the control subjects at a $\mathrm{p}$ value $<0.01$ and $<0.001$.however no significant difference in the equilibrium scores of condition 1 and 2 between the normal hearing and the hearing impaired children indicating that they are able to maintain balance by the other 2 substitutive strategies for balance control which are the somatosensory proprioceptive and visual inputs to the equilibrium centers in brain.

To know whether the 3 vestibular tests were abnormal together in the same patient or affected separately, the researcher classified the eighty hearing impaired children into 4 groups; A, B, C, and D. where group A represent the hearingimpaired children who don't have vestibular lesion i.e. normal vestibular function in all the 3 tests. These represent $45 \%$ of cases (36 patients). Group B included the hearingimpaired children with single abnormal test that's to say there is affection in one of the 3 vestibular pathways. These represent $25 \%$ of cases (20 patients). Group $C$ included the hearing-impaired children with 2 abnormal tests. These represent $20 \%$ of cases (16 patients). Group D included hearingimpaired children with abnormal results in all of the 3 results and represented 10\% (8 patients) of cases. That's to say this group has total labyrinthine agenesis which is found in major craniofacial anomalies.

\section{Hearing level in relation to vestibulocular, vestibulocollic and vestibulospinal reflexes:}

In our study, there was significant moderate correlation between severity of hearing impairment and affection of the semicircular canals mediating the vestibulocular reflex. $r=0.422$ and $P$ value $=0.03$. Also, there was significant moderate correlation between severity of hearing impairment and affection of the saccule of otolith organ mediating the vestibulocollic reflex. $\mathrm{r}=0.485$ at $\mathrm{P}$ value 0.01 and lastly, there was significant moderate correlation between severity of hearing impairment and affection of the vestibulospinal reflex pathway anyway along this highly complex and integrated pathway controlling balance. $r=0.546$ at significant $P$ value $=0.01$

Moderate correlation may be related to the character of the study group as they have varying degree (mild to profound) of hearing loss, and to the complex relationship between the auditory and vestibular function. The complexity of this interaction is particularly evident in cases where vestibular function is well preserved in the presence of even the most severe auditory dysfunction and in instances where apparently minor losses of auditory function are accompanied by complete vestibular dysfunction.

It was noted that correlation was more pronounced for the affection of vestibulospinal reflex which is actually mediated by all types of receptors, 
semicircular canals, utricle, and saccule. That's to say affection of any one of these receptors or the integrating centers for these reflexes will affect the result of posturography and will affect the equilibrium of the patient tested by this maneuver. Also, this interprets the majority of cases which was detected by SOT-CDP in comparison to the other 2 tests. SOT- CDP is considered the most sensitive test which detects abnormal vestibular function in these study groups.

In recent years, many deaf children worldwide have undergone $\mathrm{CI}$ in their early childhood. After CI, owing to the electrode wire inserted into the cochlea, cochlear and vestibular sensory cells are likely damaged $(5,17)$. The vestibular assessment of infants and young children is difficult to perform, but it must offer highly important information before and after CI.

Finally, we conclude that $90 \%$ of infants and young children who had a severe and profound hearing loss showed abnormal results in the vestibular assessment using the caloric test, computerizd dynamic posturography, and VEMP recording. We emphasize that the peripheral vestibular system including semicircular canals and saccules of deaf children should be examined. The results of these tests are highly beneficial for the management of hearing-impaired children.

It is recommended to investigate the etiology of hearing loss in addition to vestibular reflexes in these hearing-impaired children.

\section{References}

1-Arnvig, J. (1955). "Vestibular function in deafness and severe hardness of hearing." Acta Otolaryngol. Head Neck Surg 45(4): 283-288.

2-Everberg, G. (1960). "Unilateral total deafness in children clinical problems with a special view to vestibular function." Acta Otolaryngol 52: 253-269.

3-Holderbaum, F. M., S. Ritz, et al. (1979). "A study of otoneurologic and balance tests with deaf children." Am Ann Deaf 124(6): 753-9.

4- Brookhouser, P. E., D. G. Cyr, et al. (1982). "Vestibular findings in the deaf and hard of hearing." Otolaryngol Head Neck Surg 90(6): 773-7.

5- Kaga, k (2007) Assessment of vestibular function of infants and children with congenital and acquired deafness using the ice-water caloric test, rotational chair test and vestibular-evoked myogenic potential recording, Acta Otolaryngol. 127 (July (7)) (2007) 736-747.

6- Suarez, H., S. Angeli, et al. (2007). "Balance sensory organization in children with profound hearing loss and cochlear implants." Int J Pediatr Otorhinolaryngol 71(4): 629-37.

7- Murofushi, T. and I. S. Curthoys (1997). "Physiological and anatomical study of click-sensitive primary vestibular afferents in the guinea pig." Acta Otolaryngol 117(1): 66-72.

8-Rajendran V and Roy FG ( 2011) "An overview of motor skill performance and balance in hearing impaired children", tal J Pediatr. 2011; 37: 33.

9-Cushing SL, Papsin BC, Rutka JA, James AL, Gordon KA. (2008). Evidence of vestibular and balance dysfunction in children with profound sensorineural hearing loss using cochlear implants. Laryngoscope. 2008;118(10):1814-23. doi: 10.1097/MLG.0b013e31817fadfa.

10- NCHAM (2006). National Center for Hearing Assessment and Management.

11-Kelsch, T.,Schaefer, A. et al. (2006). "Vestibular evoked myogenic potentials in young children: test parameters and normative data." Laryngoscope 116(6): 895-900.

12-Kiyomizu, K., T. Tono, et al. (2000). "Dizziness and vertigo after cochlear implantation." Adv Otorhinolaryngol 57: 173-5.

13-Fina, M., M. Skinner, et al. (2003). "Vestibular dysfunction after cochlear implantation." Otol Neurotol 24(2): 23442; discussion 242.

14-Buchman, C. A., J. Joy, et al. (2004). "Vestibular effects of cochlear implantation." Laryngoscope 114(10 Pt 2 Suppl 103): 1-22.

15-Tribukait A, Brantberg K, Bergenius J. (2004) Function of semicircular canals, utricle and saccules in deaf children. Acta Otolarygol (Stockh) ; 124: 41_8.

16-O'Rahilly, R. (1963). "The Early Development of the Otic Vesicle in Staged Human Embryos." J Embryol Exp Morphol 11: 741-55.

17-Jacot E, Abbeele T , Debre HR, Sylvette R. (2009). "Vestibular 
Mohamed Abd Al-Ghaffar, Yousri Othman, Ashraf Abou-Taleb EJNSO Vol.1, No. 1; Jan (2014) 1-9

impairments pre- and post-cochlear implant in children "International Journal of Pediatric Otorhinolaryngology (2009) 73, 209-217. 